\title{
Overview of Registered Clinical Trials on Manual Therapy: Possible Implications of Genetic Testing for Personalized Treatment
}

\author{
MIKLOS POZSGAI ${ }^{1,2}$, ISTVAN SZABO $^{3,4}$, NORA NUSSER $^{1,2}$, REKA VARNAI $^{5}$ and CSILLA SIPEKY 6 \\ ${ }^{1}$ Medical School, University of Pécs, Pécs, Hungary; \\ ${ }^{2}$ Harkány Termal Rehabilitation Centre, Harkány, Hungary; \\ ${ }^{3}$ Institute of Sport Sciences and Physical Education, University of Pécs, Pécs, Hungary; \\ ${ }^{4}$ Faculty of Sciences, Doctoral School of Biology and Sportbiology, University of Pécs, Pécs, Hungary; \\ ${ }^{5}$ Department of Primary Health Care, Medical School, University of Pécs, Pécs, Hungary; \\ ${ }^{6}$ Institute of Biomedicine and Cancer Research Laboratories, \\ Western Cancer Centre FICAN West, University of Turku, Turku, Finland
}

\begin{abstract}
Background/Aim: Manual therapy (MT) is a frequently applied intervention offering individualized treatment in the clinic. In addition to the traditional approaches of MT, measuring molecular response to MT may offer better understanding of MT outcomes in order to provide specific personalized treatment. The aim of this study was to summarize MT-related registered clinical trials, as well as to search for any evidence on MT and genetics. Patients and Methods: A comprehensive search was conducted within the Clinical Trials database with predefined keywords mining for all types of MT-related clinical trials. Results: From the 47 trials, 20 had results and 27 had no results. MT alleviated pain and improved function almost in all trials. One registered clinical trial had investigated molecular outcomes of MT. Conclusion: MT is an effective and individualized treatment offering option in the management of several conditions. Interestingly, a clinical trial was found investigating molecular genetics and MT pinpointing an already existing link between genetics and MT. Therefore, further clinical trials may focus on genetics and MT for providing specific personalized treatment in future.
\end{abstract}

This article is freely accessible online.

Correspondence to: Miklós Pozsgai, Harkány Thermal Rehabilitation Centre, Zsigmondy walkway 1, 7815 Harkány, Baranya, Hungary. Tel: +36 72580900/849, e-mail: pozsgay.miklos@harkanykorhaz.hu

Key Words: Musculoskeletal manipulations, registered clinical trials, genetic testing.
Manual therapy (MT) has been defined by the International Federation of Orthopaedic Manipulative Physical Therapist (IFOMPT) as skilled hand movements, which "intend to optimize any or all of the following: improve tissue extensibility; increase range of motion; mobilize or manipulate soft tissues and joints; induce relaxation; change muscle function; stabilize the joint complex; modulate pain; reduce soft tissue swelling, inflammation or movement restriction" (1). Joint-based (including mobilization and manipulation), muscle-based and nerve-based techniques are frequently applied patient interventions that offer individualized treatment in the clinic. As the clinical effects of MT are measurable through several available investigation methods (2-4), the effect of MT has been well documented in the management of a number of different conditions, such as neck pain, shoulder pain or knee osteoarthritis (5-7), resulting in recommendation of MT in a wide range of disorders (810). Effectiveness of MT is especially well documented in clinical trials. As registration of these MT-related trials requires thorough, in-depth information, comprehensive investigation of MT clinical trials may provide details regarding the examination area and the personalized treatment effectiveness of MT. However, a systematic evaluation of MT-related clinical trials has not been conducted yet.

Personalized treatment is a key component of successful rehabilitation. As the genomic era of health care is evolving, evidence for using genetic factors for identifying disease risk as well as tailoring preventive and therapeutic regimens is growing $(11,12)$. Based on the recommendation of the American Physical Therapy Association (APTA), genetics is defined as a high priority area to advance science and improve physical therapy (13). As there is evidence suggesting a genetic influence on the clinical course of patients with osteoarthritis, 
low back pain, and cardiovascular disease, interaction between clinical genetics and physical therapy practice may be beneficial (12). In addition, genetic factors related to exercise response have been recently identified (11). As suggested by Cornwall et al., awareness of physical therapists on gene examination procedures during physical therapy rehabilitation in order to deliver even more personalized treatment might be essential in the future (12). As MT is a crucial part of physical therapy intervention, development and assessment of molecular and clinical genomics and its role in personalized MT may support this future trend.

The objective of this study was to identify and summarize all MT-related clinical trials to recognize the importance of MT in clinical practice. Therefore, interventions and outcomes in MT-related clinical trials were assessed. In addition, special attention was paid to personalized treatment options based on possible application of molecular genetic measurements in MT.

\section{Patients and Methods}

Data collection. All data was collected in June 2020. The publicly available Clinical Trials database (www.clinicaltrials.gov) was mined for the registered MT-related clinical trials. The following terms were included in the "other terms" search field: "end-range mobilization", "joint manual therapy", "joint mobilization", "manipulation", "manual therapy", "non-thrust manipulation", "nonthrust mobilization" and "thrust manipulation".

Search criteria. After initial search, the duplicated trials were excluded. Manual exclusion of trials not referring to the application of MT at peripheral joint or spine marked at the intervention column and/or in the title was also done. Since osteopathy, chiropractic and visceral therapy are not recognized MT interventions based on IFOMPT protocol (1), trials referring to the application of these techniques in the title and at the intervention column were also excluded. When MT was mentioned only at the intervention column, but without precise description of the applied technique, manual search was performed within the trial description to obtain further information. MT technique mentioned as a single intervention or as a complementary technique was accepted as eligible. In cases of more than one follow-up, the result of the last follow-up was investigated.

Structuration of MT-related trials. The identified MT-related clinical trials were divided in 2 groups: trials completed with results (Table I) and not completed before the time of the study, thus without results. In case of trials without results, no result was reported in the database. Regarding trials with results, statistically significant difference was accepted at $p \leq 0.05$. The flow diagram of the search method is displayed in Figure 1.

\section{Results}

After an initial search, 454 MT-related clinical trials have been identified. After removing the duplicates and trials not referring to MT application, 47 trials remained for further investigation. All 47 trials were interventional studies. From these, 20 trials had results, whereas 27 trials had no results. Information of trials with results, including National Clinical Trial Number (NCT number), phase, sponsor, title, condition and interventions are presented in Table I.

Trials with results. From the 20 trials with results, two trials were in phase II, one trial was in phase II/I, while the phase was not applicable for the rest 17 clinical trials (Table I).

The most investigated medical condition was low back pain $(n=6)$, referring to its importance and prevalence in the population (14). The next frequently investigated medical condition was neck pain $(n=5)$, indicating another frequently occurring musculoskeletal condition amongst the population (15). Other investigated conditions were temporomandibular joint disorder $(n=2)$, stroke $(n=1)$, cerebral palsy $(n=1)$, hemophilia $(n=1)$, cervical radiculopathy $(n=1)$, impingement syndrome $(n=1)$, thoracic spine condition $(n=1)$ and lumbar spinal stenosis $(n=1)$. Overall, 15 trials examined spine, 2 trials investigated temporomandibular joint, 2 trials measured lower extremity condition and 1 trial investigated upper extremity condition.

The following outcomes have been used in the MT-related clinical trials with results. In low back pain trials $(n=6)$, pain including visual analogue scale (VAS) and numerating pain rating scale (NPRS), range of motion (ROM) including flexion, extension, both direction of lateral flexion, biomechanics including lumbar spine stiffness (LSS) and flexion-relaxation ratio, LSS and normalized global stiffness variation, spinal segment load (SSL) alone, rate of loading for force and moment, postural sway, postural sway speed, response to sudden load and response time, muscle response per side, gait analysis, sick leave, questionnaires including Oswestry low back pain disability questionnaire (ODQ), Roland Morris low back pain disability questionnaire (RMDQ), low back leg pain intake questionnaire (LBLPIQ), patient reported outcomes measurement information scale-29 (PROMIS-29) and subjective outcomes including believability of placebo, bothersomeness, expectation for treatment effectiveness and treatment success. In neck pain trials $(n=5)$ pain including VAS and NPRS, plasma concentration, ROM including flexion, extension, both direction of lateral flexion and rotation and T1-T3 flexion, extension, both direction of lateral flexion and rotation, pressure pain threshold (PPT), questionnaires including neck disability index questionnaire (NDIQ), self-perceived global rating of change (GROC) and subjective outcome including fear avoidance belief were investigated. In temporomandibular joint disorder trials $(n=2)$, the defined outcomes were pain including VAS, ROM including opening of the jaw, PPT, questionnaires including chronic pain scale (CPS), NDIQ, sick leave, subjective outcomes including nonspecific physical symptoms with and without pain, 
Table I. Manual therapy-related clinical trials with results $(n=20)$.

\begin{tabular}{llll}
\hline NCT Number & Title Condition & Intervention arms & Results \\
Phase & & & \\
Sponsor & &
\end{tabular}

\section{NCT01168999}

Phase 1, phase 2

University of Florida

The Mechanisms
of Manual Therapy
in the Treatment
of Low Back Pain

Low back pain

\section{SM}

2. Sham SM

3. Enhanced sham SM

4. Control
NCT00939107

Phase not applicable

Back and Rehabilitation

Center, Copenhagen;

The Danish Rheumatism

Association;

The Danish Physiotherapy

Organization;

Foundation for

Chiropractic Research

and Post Graduate

Education;

The Danish Institute for

Mechanical Diagnosis

and Therapy

NCT00285649

Phase not applicable

Palmer College

of Chiropractic;

Department of Health

and Human Services

NCT01670292

Phase not applicable

Palmer College

of Chiropractic;

University of Iowa;

National Center for

Complementary and

Integrative Health

NCT00830596

Phase not applicable

Palmer College

of Chiropractic;

National Center for

Complementary

and Integrative

Health

\section{The McKenzie \\ Method Versus \\ Low back pain \\ 1. SM \\ 2. McKenzie exercises}

Manipulation for

Patients With Chronic

Low Back Pain

Predicting Patients'

Response to Spinal

Manipulation

Patient Response to Spinal Manipulation

Effect of Spinal

Manipulation on

Sensorimotor Functions

in Back Pain Patients
Low back pain

1. HVLA-SM

Low back pain

1. HVLA-SM

2. LVVA-SM

3. medical care

Low back pain

1. HVLA-SM

2. LVVA-SM

3. Sham intervention
Baseline: believability of placebo

and expectation for treatment effectiveness was greater in enhanced sham SM and SM compared to control $(p<0.01)$;

Postintervention: VAS decreased after sham SM compared to other groups with significant between-group difference $(p=0.05)$; 2-week follow-up: NPRS and ODQ

decreased in all groups without significant between-group difference $(p>0.05)$;

Flexion improved more after sham

SM compared to other groups without significant between-group difference $(p>0.05)$; Extension improved only after enhanced sham SM compared to other groups;

Both direction of lateral flexion improved more after SM compared to other groups

2-month follow-up: RMDQ decreased more without significant difference $(p>0.05)$ and treatment success improved more after McKenzie exercises compared to SM;

1-year follow-up: LBLPIQ and sick leave decreased more after SM compared to McKenzie exercises

3-week follow-up: RMDQ decreased more after HVLA-SM compared to LVVA-SM and medical care

6-week follow-up: VAS, NPRS, RMDQ and bothersomeness decreased and PROMIS-29 General Health Status Scale improved;

LSS and flexion-relaxation ratio decreased, LSS - normalized global stiffness variation remained, SSL alone and rate of loading for force and moment increased 2-week follow-up: postural sway improved more after HVLA compared to LVVA-SM and sham intervention;

Postural sway speed, response to sudden load and response time decreased more after LVVA-SM compared to HVLA-SM and sham intervention;

Muscle response per side decreased more after HVLA-SM 
in vivo $36: 294-305$ (2022)

Table I. Continued

\begin{tabular}{|c|c|c|c|c|}
\hline $\begin{array}{l}\text { NCT Number } \\
\text { Phase } \\
\text { Sponsor }\end{array}$ & Title & Condition & Intervention arms & Results \\
\hline $\begin{array}{l}\text { NCT02645123 } \\
\text { Phase not applicable } \\
\text { University of } \\
\text { Ioannina }\end{array}$ & $\begin{array}{c}\text { Gait in Low Back Pain } \\
\text { Patients After Spinal } \\
\text { Mobilization }\end{array}$ & $\begin{array}{l}\text { Chronic low } \\
\text { back pain }\end{array}$ & $\begin{array}{c}\text { 1. TENS } \\
\text { 2. SM } \\
\text { 3. Swedish type } \\
\text { massage } \\
\text { 4. Static hamstring } \\
\text { stretch } \\
\text { 5. Sham intervention }\end{array}$ & $\begin{array}{l}\text { 5-week follow-up: gait analysis improved } \\
\text { more after sham intervention compared } \\
\text { to other groups; } \\
\text { 6-month follow-up: NPRS, ODQ } \\
\text { and RMDQ decreased more after SM } \\
\text { compared to other groups }\end{array}$ \\
\hline $\begin{array}{l}\text { NCT00566930 } \\
\text { Phase not applicable } \\
\text { Université du Québec } \\
\text { à Trois-Rivières, } \\
\text { Foundation for } \\
\text { Chiropractic } \\
\text { Education } \\
\text { and Research }\end{array}$ & $\begin{array}{l}\text { Preventive Care of } \\
\text { Chronic Cervical Pain } \\
\text { and Disabilities }\end{array}$ & Neck pain & $\begin{array}{c}\text { 1. SM } \\
\text { 2. SM+exercises }\end{array}$ & $\begin{array}{l}\text { 10-month follow-up: VAS decreased } \\
\text { more after SM compared to SM+exercises }\end{array}$ \\
\hline $\begin{array}{l}\text { NCT03194490 } \\
\text { Phase not applicable } \\
\text { Loma Linda } \\
\text { University }\end{array}$ & $\begin{array}{l}\text { Benefit of Adding } \\
\text { Stretching to Standard } \\
\text { Intervention For Patients } \\
\text { With Nonspecific } \\
\text { Mechanical Neck Pain }\end{array}$ & $\begin{array}{l}\mathrm{c} \\
\mathrm{p} \\
(\mathrm{c}\end{array}$ & $\begin{array}{l}\text { 1. Combined intervention } \\
\text { (cervical passive mobilization, } \\
\text { passive stretching and home } \\
\text { program: ROM exercises) } \\
\text { 2. Standard intervention } \\
\text { (cervical passive mobilization } \\
\text { and home program: } \\
\text { ROM exercises) }\end{array}$ & $\begin{array}{l}\text { 8-week follow-up: except left lateral } \\
\text { flexion improved more after standard } \\
\text { intervention compared to combined } \\
\text { intervention, all other direction of ROM } \\
\text { improved in both groups; } \\
\text { NPRS and NDIQ decreased, } \\
\text { GROC and PPT improved more } \\
\text { after combined intervention } \\
\text { compared to standard intervention }\end{array}$ \\
\hline $\begin{array}{l}\text { NCT02435966 } \\
\text { Phase not applicable } \\
\text { University European } \\
\text { of Madrid }\end{array}$ & $\begin{array}{l}\text { Dry Needling in Patients } \\
\text { With Chronic Neck Pain }\end{array}$ & Neck pain & $\begin{array}{l}\text { 1. Control } \\
\text { 2. MT+sham DN } \\
\text { 3. MT+DN }\end{array}$ & $\begin{array}{l}\text { 30-day follow-up: VAS decreased } \\
\text { more after MT+DN compared to } \\
\text { MT+sham DN and Control }\end{array}$ \\
\hline $\begin{array}{l}\text { NCT03176654 } \\
\text { Phase not applicable } \\
\text { Loma Linda } \\
\text { University }\end{array}$ & $\begin{array}{l}\text { The Effect of Manipulation } \\
\text { of the Cervical Spine } \\
\text { on Pain Biomarkers }\end{array}$ & $\begin{array}{l}\text { Posterior } \\
\text { neck pain }\end{array}$ & $\begin{array}{l}\text { 1. HVLAT manipulation } \\
\text { 2. Sham HVLAT } \\
\text { manipulation }\end{array}$ & $\begin{array}{l}\text { Postintervention: plasma } \\
\text { concentration improved more } \\
\text { after HVLAT manipulation } \\
\text { compared to HVLAT manipulation }\end{array}$ \\
\hline $\begin{array}{l}\text { NCT02691143 } \\
\text { Phase not applicable } \\
\text { Sport and Spine Rehab } \\
\text { Clinical Research } \\
\text { Foundation }\end{array}$ & $\begin{array}{l}\text { The Effect of TheraBand } \\
\text { Kinesiology Tape on } \\
\text { Post-manipulation Pain } \\
\text { and Range of Motion }\end{array}$ & $\begin{array}{c}\text { Acute } \\
\text { non-complicated } \\
\text { postural neck pain }\end{array}$ & $\begin{array}{l}\text { 1. SM } \\
\text { 2. SM and TheraBand } \\
\text { kinesiology tape }\end{array}$ & $\begin{array}{c}\text { 24-48 h follow-up: all direction of } \\
\text { T1-T3 ROM improved more and } \\
\text { NPRS decreased more after SM and } \\
\text { TheraBand kinesiology tape } \\
\text { compared to SM }\end{array}$ \\
\hline $\begin{array}{l}\text { NCT03454581 } \\
\text { Phase } 2 \\
\text { Federal University } \\
\text { of Rio Grande } \\
\text { do Sul }\end{array}$ & $\begin{array}{l}\text { Effectiveness of } \\
\text { Photobiomodulation and } \\
\text { Manual Therapy Alone } \\
\text { or Combined in } \\
\text { Temporomandibular } \\
\text { Dysfunction Patients }\end{array}$ & $\begin{array}{l}\text { Temporomandibular } \\
\text { disorder }\end{array}$ & $\begin{array}{l}\text { 1. Photobiomodulation } \\
\text { 2. MT (mobilization } \\
\text { of the jaw, MPRT) } \\
\text { 3. Photobiomodulation } \\
+ \text { MT }\end{array}$ & $\begin{array}{l}\text { 90-day follow-up: VAS decreased }(p<0.001), \\
\text { CPS and all directions of jaw ROM } \\
\text { decreased }(p=0.05) \text {, depression decreased } \\
(p<0.05) \text {, nonspecific physical symptoms } \\
\text { with pain decreased }(p<0.01) \text {, nonspecific } \\
\text { physical symptoms without pain, } \\
\text { mandibular function and anxiety increased } \\
(p=0.05) \text { in all groups }\end{array}$ \\
\hline $\begin{array}{l}\text { NCT03619889 } \\
\text { Phase not applicable } \\
\text { Universidad } \\
\text { Complutense } \\
\text { de Madrid }\end{array}$ & $\begin{array}{c}\text { The Effectiveness } \\
\text { of a Physiotherapy } \\
\text { Technique in Patients } \\
\text { With Chronic Myofascial } \\
\text { Temporomandibular } \\
\text { Disorder }\end{array}$ & $\begin{array}{l}\text { Temporomandibular } \\
\text { disorder }\end{array}$ & $\begin{array}{l}\text { 1. MPRT on trigger } \\
\text { points } \\
\text { 2. Sham intervention }\end{array}$ & $\begin{array}{l}\text { 3-month follow-up: VAS and } \\
\text { depression decreased in both groups } \\
\qquad(p<0.001) \text {; } \\
\text { ROM of opening decreased in both groups; } \\
\text { PPT, kinesiophobia, catastrophizing, } \\
\text { state anxiety, trait anxiety, trait depression } \\
\text { decreased more after MPRT compared } \\
\text { to sham intervention; } \\
\text { NDIQ improved more after MPRT compared } \\
\text { to sham intervention }\end{array}$ \\
\hline
\end{tabular}

Table I. Continued 
Table I. Continued

\begin{tabular}{llll}
\hline NCT Number & Title & Condition & Intervention arms \\
Phase & & & Results \\
Sponsor & &
\end{tabular}

\section{NCT02667821 \\ Phase not applicable Canadian Memorial Chiropractic College; National Chiropractic Mutual Insurance Company}

\author{
NCT01207570 \\ Phase 2 \\ The Hong Kong \\ Polytechnic \\ University; \\ Phoelia co. ltd. \\ NCT02198040 \\ Phase not applicable \\ Universidad Católica \\ San Antonio de Murcia
}

\author{
Vertebral artery \\ dissection, \\ cerebrovascular \\ accident, stroke
1. Neutral neck position
2. Neutral head position 3. SM

Positions \& Manipulation in Patients With Neck Pain

\begin{abstract}
Endermotherapy for Children With Developmental Disabilities
\end{abstract}

Physiotherapy in the Haemophilic Arthropathy of the Elbow

\section{Developmental delay in cerebral palsy}
1. Endermotherapy
2. Passive manual stretching

\section{Patients with} hemophilia

1
mobilization of elbow, passive muscle stretching, proprioceptive
1. MT (termo/cryotherapy, neuromuscular function) 2. Education

\section{NCT02081456 \\ Phase not applicable \\ University of Nevada \\ NCT01190891 \\ Phase not applicable \\ Madigan Army \\ Medical Center; \\ University of Puget \\ Sound; Franklin \\ Pierce University \\ NCT02550132 \\ Phase not applicable \\ Université du Québec \\ à Trois-Rivières, \\ Fondation Chiropratique du Québec \\ NCT01943435 \\ Phase not applicable \\ Patient-Centered \\ Outcomes Research \\ Institute; University \\ of Pittsburgh}

Soft Tissue Mobilization

Versus Therapeutic

Ultrasound for Subjects

With Neck and Arm Pain

Physical Therapy

Versus Steroid Injection

for Shoulder Impingement Syndrome

The Role of the Rate

of Force Application

in Responses to

Spinal Manipulation

Therapy
Study Comparing
3 Different
Treatments for
Arthritis of the
Lower Back
(Lumbar Spinal Stenosis)

$\begin{array}{cc}\begin{array}{c}\text { Cervical } \\ \text { radiculopathy }\end{array} & \begin{array}{c}\text { 1. Soft tissue } \\ \text { mobilization } \\ \text { 2. Therapeutic } \\ \text { ultrasound }\end{array} \\ \begin{array}{c}\text { Shoulder } \\ \text { impingement } \\ \text { syndrome }\end{array} & \begin{array}{c}\text { 1. MT (mobilization } \\ \text { of the joints around } \\ \text { the shoulder and } \\ \text { cervical/thoracic spine) } \\ \end{array} \\ & \text { 2. Corticosteroid } \\ \text { injection }\end{array}$

$\begin{array}{cc}\text { Spinal } & 1 . \mathrm{SM} \\ \text { manipulation } & \begin{array}{c}\text { 2. Apparatus used } \\ \text { to deliver SM-s }\end{array}\end{array}$

Lumbar
spinal
stenosis

\section{Medical care: NSAIDs, adjunctive analgesics,}

adjunctive anti-depressants; lumbar epidural injection

2. MT+exercise: (mobilization of the spine, sacroiliac and hip joint); individualized exercises in clinical setting

3. Exercise: group exercise in community setting
Postintervention: blood flow through vertebral artery increased after neutral neck position and SM compared to neutral head position; 1-year follow-up: blood flow through vertebral artery increased after neutral head position compared to SM and neutral neck position; tissue perfusion increased more after SM compared to neutral neck and head position

1-day follow-up: passive ankle ROM increased more after passive manual stretching compared to endermotherapy; 4-day follow-up: passive ankle ROM increased more after endermotherapy compared to manual stretching

1-month prior beginning of the trial: frequency of elbow hemarthrosis decreased after education compared to MT;

6-month follow-up: elbow flexion ROM, circumference of arm and biceps strength increased, VAS decreased more after MT compared to education 2-4 days follow-up: NPRS, ULNT and NDIQ decreased and PSFS increased after soft tissue mobilization compared to therapeutic ultrasound 1-year follow-up: SPADI decreased more after MT compared to corticosteroid injection;

GROC increased similar in both groups

Postintervention: RMS and vertebral
displacement increased after SM
performed with the most Newton

8-week follow-up: SSS decreased after MT+exercise without significant difference compared to medical care $(p=0.02)$ and exercise $(p=0.01)$;

SPWT increased after MT+exercise without significant difference compared to medical care $(p=0.10)$ and exercise $(p=0.61)$;

SWA decreased after MT+exercise without significant difference compared to medical care $(p=0.16)$ and exercise $(p=0.40)$

CPS: Chronic pain scale; DN: dry needling; FRR: flexion-relaxation ratio; GROC: global rating of change; HVLAT, HVLA: high-velocity lowamplitude; HVLA-SM: high-velocity low-amplitude spinal manipulation; LBLPIQ: low back leg pain intake questionnaire; LVVA-SM: low-velocity, variable amplitude spinal manipulation; LSS: lumbar spine stiffness; MPRT: manual pressure release technique; MT: manual therapy; NCT number: national clinical trial number; NDIQ: neck disability index questionnaire; NPRS: numerating pain rating scale; NSAID: non-steroidal anti-inflammatory drug; ODQ: Oswestry low back pain disability questionnaire; PPT: pressure pain threshold; PSFS: patient specific functional scale; PROMIS-29: patientreported outcomes measurement information system; QOL: quality of life; RMDQ: Roland Morris low back pain disability questionnaire; RMS: root mean square; ROM: range of motion; Sham intervention: placebo intervention; SM: spinal manipulation; SPADI: shoulder pain and disability index; SPWT: self-paced walking test; SSL: spinal segment load; SSS: swiss spinal stenosis; SWA: sense wear armband; TENS: transcutan electro neuro stimulation; ULNT: upper limb neural tension test; VAS: visual analogue scale; WOMAC: Western Ontario and McMaster universities arthritis index. 


\author{
RECORDS IDENTIFIED through search \\ of clinicaltrials.gov: \\ "Manual therapy" $n=197$ \\ "Manipulation" n=189 \\ "Joint mobilization" $n=20$ \\ "Non-thrust manipulation" $n=15$ \\ "End-range mobilization" $\mathrm{n}=13$ \\ "Non-thrust mobilization" $\mathrm{n}=10$ \\ "Joint manual therapy" $n=6$ \\ "Thrust manipulation" $\mathrm{n}=4$
}

OVERALL INCLUDED TRIALS: $\mathrm{n}=454$

\title{
RECORD EXCLUDED
}

$\mathrm{n}=33$

Reason for exclusion: duplicated registered trials

RECORDS REMAINED after duplicates removed

$\mathrm{n}=\mathbf{4 2 1}$

\section{CLINICAL TRIALS ASSESSED} $\mathrm{n}=\mathbf{4 7}$

Figure 1. Flow diagram of search strategy for clinical trials in manual therapy.

mandibular function, depression, kinesiophobia, state anxiety, trait anxiety, trait depression, catastrophizing, anxiety, cost effectiveness and bothersomeness. In the stroke trial, blood flow and tissue perfusion; in the cerebral palsy trial passive ankle ROM were assessed. The hemophilia trial investigated pain including VAS, extremity circumference, elbow flexion ROM, MS including musculus biceps brachii and frequency of hemarthrosis as outcome. The cervical radiculopathy trial inspected pain including VAS, neurodynamics including upper limb neural tension test (ULNT), questionnaires including NDIQ and patient specific functional scale (PSFS). In the impingement trial, two scales were used including the shoulder pain and disability index (SPADI) and GROC. In the thoracic spine trial, biomechanics including root mean square 
(RMS) and vertebral displacement were explored. Finally, in the lumbar spinal stenosis trial, the self-paced walking test (SPWT) as well as the sense wear armband (SWA) and a questionnaire including Swiss spinal stenosis (SSS) were used as outcomes.

The results of MT effectiveness can be summarized as follows: in low back pain trials, VAS decreased immediately, NPRS, ROM and ODQ decreased at 2-week follow-up, RMDQ decreased and treatment success improved at 2month follow-up, LBLPIQ and sick leave decreased at 1year follow-up, RMDQ decreased at 3-week follow-up, VAS, NPRS, RMDQ and bothersomeness decreased, PROMIS-29 and biomechanics enhanced at 6-week follow-up, biomechanics augmented at 2-week follow-up, gait improved at 5-week follow-up, NPRS, ODQ and RMDQ decreased at 6-month follow-up. In neck pain trials, VAS decreased at 10month follow-up, ROM including all directions, PPT and GROC improved and NPRS and NDIQ decreased at 8-week follow-up, VAS decreased at 30-day follow-up, plasma concentration developed immediately, ROM including all directions improved and NPRS decreased at 24-48 h followup. In temporomandibular joint disorder trials VAS, CPS, ROM, depression, nonspecific physical symptoms with and without pain and anxiety decreased at 90-day follow-up, VAS, depression, PPT, kinesiophobia, catastrophizing, state anxiety, trait anxiety, trait depression decreased, ROM including opening and NDIQ improved at 3-month followup. Blood flow developed immediately, and blood flow and tissue perfusion increased at 1-year follow-up in the stroke trial. Passive ankle ROM was better at 1-day follow-up according to the cerebral palsy trial. In the hemophilia trial, the frequency of elbow hemarthrosis decreased at 1-month prior beginning of the trial, flexion ROM, circumference of arm and biceps strength increased and VAS decreased at 6month follow-up. NPRS, ULNT and NDIQ decreased and PSFS increased at 2-4-day follow-up reported by the cervical radiculopathy trial. In the impingement trial, SPADI decreased and GROC improved at 1-year follow-up; in the thoracic spine trial, the biomechanics developed immediately. SPWT, SWA and SSS enhanced at 8-week follow-up according to the lumbar spinal stenosis trial. In summary, MT improved almost all subjective and objective outcomes both short-term and long-term in several investigated conditions.

MT was used as single intervention in the majority of trials $(n=18)$, while only 2 trials combined MT with another intervention. From the 18 trials, 11 trials applied spinal manipulation underlining the importance of using manipulation. From the remaining 7 trials, 2 applied mobilization, 3 applied muscle-based MT and 2 trials applied both mobilization and muscle-based technique. Two trials investigated MT in combination with exercise therapy and both trials presented superior outcomes.
The MT-related clinical trials were completed at 8 locations around the world including United States $(n=11)$, Canada $(n=3)$, Spain $(n=3)$, Brazil $(n=1)$, China $(n=1)$ and Denmark $(n=1)$. The main sponsors or collaborators in the trials with results were Palmer College of Chiropractic $(n=4)$, National Center for Complementary and Integrative Health $(n=3)$, University of Iowa $(n=2)$ and Loma Linda University $(n=2)$.

Trials without results. From the 27 trials without results, 2 trials were in phase III, 1 trial was in phase III and II, 3 trials were in phase II, 1 trial was in phase II and I and 1 trial was in phase I. In 19 trials, the phase was not applicable.

The most investigated condition was neck pain $(n=7)$. The next frequently investigated condition was knee osteoarthritis $(n=4)$. Further investigated conditions in decreasing order were cervicogen headache $(n=3)$, low back pain $(n=3)$, shoulder pain $(n=2)$, ankle sprain $(n=2)$, fibromyalgia and chronic fatigue syndrome $(n=1)$, adhesive capsulitis $(n=1)$, hip osteoarthritis $(n=1)$, sacroiliac joint pain $(n=1)$, hamstring injury $(n=1)$ and knee pain $(n=1)$. Overall, 11 trials examined spine, 9 trials measured lower extremity condition, 3 trials investigated cervicogenic headache, 3 trials investigated upper extremity condition and 1 trial examined the whole body.

The following outcomes have been used in the MTrelated clinical trials without results. In neck pain trials, pain including VAS and NPRS, ROM including all directions and upper cervical flexion and extension, MS including deep cervical flexor endurance test (DCFET), blood oxygen level (BOL), questionnaires including NDIQ, self-perceived GROC, headache impact test (HIT), patient acceptable symptom state (PASS), PSFS and subjective outcome including percent recovery have been assessed. Outcomes of knee osteoarthritis trials were pain including VAS and NPRS, ROM including flexion and extension, MS including musculus quadriceps femoris and hamstring muscles, functional tests including timed up and go test (TUG), six-minute walking test (6MWT), PPT, passive tension (PT) of knee, questionnaires including Western Ontario and McMaster Universities arthritis index (WOMAC) and Leeds assessment of neuropathic symptoms and signs (LANSS). Cervicogen headache trials estimated pain including NPRS, ROM including all directions, questionnaires including NDIQ, HIT, PASS, GROC and subjective outcomes, as headache duration (HAD), headache frequency (HAF), headache intensity (HAI), medication intake and analgesic use. Outcomes of low back pain trials were pain including NPRS, muscle thickness including musculus transversus abdominis, questionnaires ODQ, fear-avoidance beliefs questionnaire (FABQ) and GROC and subjective outcome including overall treatment success. Shoulder pain trials evaluated pain including 
NPRS, pain-free ROM, questionnaires including shoulder pain and disability index (SPADI), disability of arm, shoulder and hand index (QuickDASH) and modified FABQ and GROC. Outcomes of ankle sprain trials included ROM dorsalflexion, corticospinal motor excitability, muscle activation and functional tests including Single leg squat reach test (SLSRT) and ankle flexibility test (AFT) performed in standing against a wall and lying down (on stomach) and star excursion balance test (SEBT). In fibromyalgia (FM) and chronic fatigue syndrome (CFS) trial, pain including VAS and fibromyalgia impact questionnaire (FIQ), fatigue including multidimensional fatigue inventory (MFI), gene expression including ribonucleic-acid sequence (RNAseq), autonomic nervous system dysfunction including plantar pressure maps (PPM), questionnaire including 36-item short form survey (SF-36) and Likert scale and an anonymized satisfaction questionnaire have been used as outcomes. Adhesive capsulitis trial assessed SPADI, subjective outcomes including percent of normal functional capacity, activity limitations and medication use. Hip osteoarthritis trial estimated pain including VAS, passive ROM, functional tests including TUG, fast paced walking test (FPWT), stair climb test (SCT), 30-second chair stand test (30SCST) and questionnaire including WOMAC. Sacroiliac joint pain trial allowed NPRS, questionnaire including ODQ and subjective outcome including medication intake. In hamstring injury trial lumbar and hamstring ROM and biomechanics including electromyography (EMG); in knee pain trial pain including NPRS and MS were evaluated.

MT was used as single intervention in the majority of trials $(n=22), \quad 10$ of which used mobilization and 1 used manipulation. Seven clinical trials compared the effectiveness of manipulation over mobilization and 1 trial compared the effectiveness of joint mobilization compared to spinal mobilization. MT technique was combined with other, nonMT-related intervention in 5 trials, 4 of which used manipulation, and only 1 trial used mobilization. Only 1 trial investigated the effect of manipulation over mobilization in combination with non-MT-related intervention.

Reflecting on our additional goal to investigate the possible application of genetic measurements in personalized MT treatment, one registered clinical trial evaluating molecular response of MT in FM and CFS was identified (NCT04174300). This is the first MT-related, registered clinical trial involving molecular genetic measurements. Female patients fulfilling Canadian and international CFS criteria, presenting comorbid FM assessed by the American College of Rheumatology 2010, aged between 45-55 and body mass index (BMI) $<35(n=40)$ were subjected to 8 sessions of MT including pressure maneuvers of about $4.5 \mathrm{~N}$ performed twice weekly for 25 min. Blood samples were obtained before and after the first, the fourth and last treatment to determine molecular blood changes. Peripheral blood molecular cells (PBMC) transcriptome was studied before and after MT to identify treatment-associated differential expression of genes. Patient pain was monitored by VAS and FIQ, MFI, gene expression by RNAseq, autonomic nervous system dysfunction by PPM, health status by SF-36 and Likert Scale and an anonymized satisfaction questionnaire to register potential undesired secondary effects.

These MT-related clinical studies were completed at 6 locations around the world including United States $(n=16)$, Spain $(n=4)$, Hungary $(n=3)$, Great Britain $(n=2)$, India $(n=1)$ and Saudi Arabia $(n=1)$. The main sponsors or collaborators in the trials without results were University of Pecs $(n=3)$, Universidad Rey Juan Carlos $(n=3)$, Alabama Physical Therapy \& Acupuncture $(n=3)$, Universidad de Zaragoza $(n=2)$ and University of Colorado $(n=2)$.

\section{Discussion}

To the best of our knowledge, this is the first comprehensive study to summarize and interpret MT-related, registered clinical trials and to investigate the possibility of specific personalized treatment based on genetics in MT. According to the results of the present study, MT may lead to effective management of a wide range of common pathological conditions. Furthermore, a clinical trial was found investigating the molecular response after MT, thus specific personalized treatment could be forthcoming. Since not all MT-related clinical trials had results, findings of trials with and without results were discussed separately, while only objective outcomes were evaluated. The only one clinical trial investigating genetic factors is discussed more thoroughly.

From the 20 MT-related trials with results, the two most frequently investigated medical conditions were low back pain and neck pain, both frequent morbidities in the population and significant causes of sick leave (16). MT was effective in the management of these conditions, as it has also been stated in previous systematic reviews $(17,18)$. Interestingly, the next most investigated condition was temporomandibular joint disorder, in consistence with its emerging prevalence in adults (19). MT was presented as an appropriate technique in the management of this disorder in the studied clinical trials, in agreement with the findings of a previous systematic review (20). Furthermore, several other disorders were also investigated in trials with results and MT has been shown effective in the management of pain and physical function; however, previous findings already presented MT effective in these conditions (10, 2125). All these investigated conditions were frequent disorders in practice, except congenital hemophilia and cerebral palsy. Therefore, the effect of MT was explored in 
common and serious diseases. Application of MT was found as an effective approach in a wide range of conditions. However, further investigation of MT would for clarify its efficacy in a broader spectrum of clinical conditions.

Interestingly, many objective outcomes examined in the MT-related trials with results could be recognized as routinely used in clinical trials. These outcomes included evaluation of the measured condition including assessment of pain intensity, functional measurement of the impaired joint, functional tests, biomechanics and neurodynamic. On the other hand, blood flow and tissue perfusion are not routinely assessed; therefore, future MT clinical trials could investigate also blood circulation-associated outcomes.

MT was applied in many trials alone or in combination to another non-MT-related intervention. It has been suggested that application of MT additionally with physical therapy may lead to greater improvement in alleviation of pain and development of physical function, compared to MT alone (33); however, most MT-related trials with results compared MT to another type of MT in contrast to exercise therapy. Based on the trials results, MT applied alone or in combination with exercise therapy may be effective in the management of low back pain and neck pain, temporomandibular disorder, cerebral palsy, hemophilia, cervical radiculopathy, shoulder impingement syndrome and lumbar spine stenosis. Furthermore, spinal manipulation was implemented more frequently compared to mobilization in the investigated spine condition trials. This can be of interest, because manipulation is restricted to medical doctors in some countries and education of manipulation requires more time compared to mobilization. A recently published meta-analysis (34) suggested the effectiveness of both manipulation and mobilization in the management of chronic lumbar back pain; however, manipulation appeared to produce a greater effect regarding alleviation of pain and disability compared to mobilization. Therefore, further systematic reviews and meta-analyses may focus on the possible benefit of these techniques in different medical conditions.

In the 27 trials without results, the most investigated condition was neck pain. Interestingly, knee osteoarthritis was the next frequently explored condition underlining its frequent occurrence in the elderly population (35). MT has been applied in wide range of conditions in clinical trials without results but beyond mentioning the efficacy of MT; however, the positive effects of MT in these conditions have already been presented $(10,17-18,33,36-44)$. Interestingly, treatment of painful areas may also contribute to alleviation of pain in adjacent joints $(6,45)$. Therefore, examination of the adjacent joints or spinal segments after MT could be useful for manual therapists in practice.

The link between MT and genetics has not been well established yet. The APTA defines genetics as a high priority area in order to advance science and improve exercise therapy. According to APTA, the possible results of the different gene expressions planned to be measured in trials are highly innovative and may give insight into the genes involved in response to exercise therapy (13). Based on Curtis et al., "exercise genomics" may lead to more individualized prescriptions aiming to improve the effectiveness of exercise therapy (11). Therefore, investigating the role of genetics in exercise therapy practice has been already started in clinic. Genetic influence on the clinical course as well as internal and external factors of patients with different conditions has been previously documented (12). In addition, individual responsiveness to interventions has been shown for many conditions based on recommendation of clinical guidelines (12). Thus, the connection between genetics and exercise therapy has been well underlined by now. As a consequence, prevention of chronic conditions could also be feasible (11). As MT can be individualized for each patient, genetic information in addition to MT could improve personalized treatment in practice. Interestingly, one clinical trial was already performed investigating the link between MT and genetics. The clinical trial involved female patients with carpal tunnel syndrome receiving either 3 sessions of MT or decompression surgery, where pain and function outcomes were assessed in connection with Val158Met polymorphism. Nevertheless, no significant difference was observed at 1-year follow-up in alleviation of pain or improvement of physical function after MT intervention (46). Therefore, it would be advisable to perform further MT-related clinical trials focusing on the investigation of MT and genetic outcomes.

Regarding the location of the trials, the majority of MT trials with or without results were conducted in United States and Spain, followed by Canada, Hungary and Great Britain. Although MT is widely used to treat patients worldwide, research interest on the efficacy of MT seems to differ among countries.

Database of Clinical Trials contains probably the highest number of registered clinical trials worldwide. Thus, the targeted database of our comprehensive search was Clinical Trials, but no other database got involved. However, we cannot leave out of consideration that other MT-related clinical trials and clinical trials regarding MT and genetics may exist. Moreover, not all registered trials had results and not every MT technique was applied in the investigated registered trials contributing to a non-clear picture regarding MT. Besides, MT techniques applied in the investigated trials are not precisely standardized and defined. Furthermore, comprehensive summary cannot be provided regarding the different MT interventions due to absence of statistical analysis.

\section{Conclusion}

Based on the results of the present comprehensive search, MT is a frequently applied and successful intervention in the 
management of different medical conditions offering personalized treatment. Furthermore, one registered MTrelated clinical trial investigated genetic outcomes after MT, pinpointing the potential link between MT and genetics. Future clinical trials may focus on genetics after MT for enlarging the already existing connection.

\section{Conflicts of Interest}

The Authors declare that they have no conflicts of interest.

\section{Authors' Contributions}

Pozsgai M: acquisition and analysis of data, drafting the article. Szabo I: acquisition and analysis of data. Nusser N: acquisition and analysis of data, final approval. Varnai R: analysis of data, drafting the article, final approval. Sipeky C: design of the study, drafting the article, final approval.

\section{Acknowledgements}

The Authors thank for all the technical and financial support of the institutes.

\section{References}

1 International Federation of Orthopaedic Manipulative Physical Therapists (IFOMPT). Educational Standards in Orthopaedic Manipulative Therapy: Part A. Available at: https://www.ifompt.org/ site/ifompt/IFOMPT\%20Standards\%20Document\%20definitive \%202016.pdf [Last accessed on March 16 ${ }^{\text {th }}, 2016$ ]

2 Alkhawajah HA and Alshami AM: The effect of mobilization with movement on pain and function in patients with knee osteoarthritis: a randomized double-blind controlled trial. BMC Musculoskelet Disord 20(1): 452, 2019. PMID: 31627723. DOI: 10.1186/s12891-019-2841-4

3 Ghaderi F, Jafarabadi MA and Javanshir K: The clinical and EMG assessment of the effects of stabilization exercise on nonspecific chronic neck pain: A randomized controlled trial. J Back Musculoskelet Rehabil 30(2): 211-219, 2017. PMID: 27472855. DOI: 10.3233/BMR-160735

4 Fathollahnejad K, Letafatkar A and Hadadnezhad M: The effect of manual therapy and stabilizing exercises on forward head and rounded shoulder postures: a six-week intervention with a onemonth follow-up study. BMC Musculoskelet Disord 20(1): 86, 2019. PMID: 30777064. DOI: 10.1186/s12891-019-2438-y

5 Beltran-Alacreu H, López-de-Uralde-Villanueva I, FernándezCarnero $\mathrm{J}$ and La Touche R: Manual therapy, therapeutic patient education, and therapeutic exercise, an effective multimodal treatment of nonspecific chronic neck pain: a randomized controlled trial. Am J Phys Med Rehabil 94(10 Suppl 1): 887-897, 2015. PMID: 25888653. DOI: 10.1097/PHM.0000000000000293

6 Mintken PE, McDevitt AW, Cleland JA, Boyles RE, Beardslee AR, Burns SA, Haberl MD, Hinrichs LA and Michener LA: Cervicothoracic manual therapy plus exercise therapy versus exercise therapy alone in the management of individuals with shoulder pain: a multicenter randomized controlled trial. J
Orthop Sports Phys Ther 46(8): 617-628, 2016. PMID: 27477473. DOI: $10.2519 /$ jospt.2016.6319

7 Kaya Mutlu E, Ercin E, Razak Ozdıncler A and Ones N: A comparison of two manual physical therapy approaches and electrotherapy modalities for patients with knee osteoarthritis: A randomized three arm clinical trial. Physiother Theory Pract 34(8): 600-612, 2018. PMID: 29308949. DOI: 10.1080/ 09593985.2018.1423591

8 Geenen R, Overman CL, Christensen R, Åsenlöf P, Capela S, Huisinga KL, Husebø MEP, Köke AJA, Paskins Z, Pitsillidou IA, Savel C, Austin J, Hassett AL, Severijns G, Stoffer-Marx M, Vlaeyen JWS, Fernández-de-Las-Peñas C, Ryan SJ and Bergman S: EULAR recommendations for the health professional's approach to pain management in inflammatory arthritis and osteoarthritis. Ann Rheum Dis 77(6): 797-807, 2018. PMID: 29724726. DOI: 10.1136/annrheumdis-2017-212662

9 Gross A, Langevin P, Burnie SJ, Bédard-Brochu MS, Empey B, Dugas E, Faber-Dobrescu M, Andres C, Graham N, Goldsmith $\mathrm{CH}$, Brønfort G, Hoving JL and LeBlanc F: Manipulation and mobilisation for neck pain contrasted against an inactive control or another active treatment. Cochrane Database Syst Rev (9): CD004249, 2015. PMID: 26397370. DOI: 10.1002/14651858. CD004249.pub4

10 Steuri R, Sattelmayer M, Elsig S, Kolly C, Tal A, Taeymans J and Hilfiker R: Effectiveness of conservative interventions including exercise, manual therapy and medical management in adults with shoulder impingement: a systematic review and meta-analysis of RCTs. Br J Sports Med 51(18): 1340-1347, 2017. PMID: 28630217. DOI: 10.1136/bjsports-2016-096515

11 Curtis CL, Goldberg A, Kleim JA and Wolf SL: Translating genomic advances to physical therapist practice: a closer look at the nature and nurture of common diseases. Phys Ther 96(4): 570-580, 2016. PMID: 26637647. DOI: 10.2522/ptj.20150112

12 Cornwall J, Elliott JM, Walton DM and Osmotherly PG: Clinical genomics in physical therapy: Where to from here? Phys Ther 98(9): 733-736, 2018. PMID: 29893975. DOI: $10.1093 / \mathrm{ptj} / \mathrm{pzy} 069$

13 American Physical Therapy Assocation (APTA). Genetics in physical therapy overview. Available at: https://www.apta.org/ patient-care/interventions/genetics/genetics-overview [Last accessed on April 19th, 2019]

14 Hartvigsen J, Hancock MJ, Kongsted A, Louw Q, Ferreira ML, Genevay S, Hoy D, Karppinen J, Pransky G, Sieper J, Smeets RJ, Underwood M and Lancet Low Back Pain Series Working Group: What low back pain is and why we need to pay attention. Lancet 391(10137): 2356-2367, 2018. PMID: 29573870. DOI: 10.1016/S0140-6736(18)30480-X

15 Cohen SP: Epidemiology, diagnosis, and treatment of neck pain. Mayo Clin Proc 90(2): 284-299, 2015. PMID: 25659245. DOI: 10.1016/j.mayocp.2014.09.008

16 Hallman DM, Holtermann A, Björklund M, Gupta N and Nørregaard Rasmussen CD: Sick leave due to musculoskeletal pain: determinants of distinct trajectories over 1 year. Int Arch Occup Environ Health 92(8): 1099-1108, 2019. PMID: 31165308. DOI: 10.1007/s00420-019-01447-y

17 de Luca KE, Fang SH, Ong J, Shin KS, Woods S and Tuchin PJ: The effectiveness and safety of manual therapy on pain and disability in older persons with chronic low back pain: a systematic review. J Manipulative Physiol Ther 40(7): 527-534, 2017. PMID: 29079255. DOI: 10.1016/j.jmpt.2017.06.008 
18 Hidalgo B, Hall T, Bossert J, Dugeny A, Cagnie B and Pitance $\mathrm{L}$ : The efficacy of manual therapy and exercise for treating nonspecific neck pain: A systematic review. J Back Musculoskelet Rehabil 30(6): 1149-1169, 2017. PMID: 28826164. DOI: 10.3233/BMR-169615

19 Pantoja LLQ, de Toledo IP, Pupo YM, Porporatti AL, De Luca Canto G, Zwir LF and Guerra ENS: Prevalence of degenerative joint disease of the temporomandibular joint: a systematic review. Clin Oral Investig 23(5): 2475-2488, 2019. PMID: 30311063. DOI: 10.1007/s00784-018-2664-y

20 de Melo LA, Bezerra de Medeiros AK, Campos MFTP, Bastos Machado de Resende CM, Barbosa GAS and de Almeida EO: Manual therapy in the treatment of myofascial pain related to temporomandibular disorders: a systematic review. J Oral Facial Pain Headache 34(2): 141-148, 2020. PMID: 32255579. DOI: $10.11607 /$ ofph. 2530

21 Anttila H, Autti-Rämö I, Suoranta J, Mäkelä M and Malmivaara A: Effectiveness of physical therapy interventions for children with cerebral palsy: a systematic review. BMC Pediatr 8: 14, 2008. PMID: 18435840. DOI: 10.1186/1471-2431-8-14

22 Cuesta-Barriuso R, Gómez-Conesa A and López-Pina JA: Manual and educational therapy in the treatment of hemophilic arthropathy of the elbow: a randomized pilot study. Orphanet J Rare Dis 13(1): 151, 2018. PMID: 30176883. DOI: 10.1186/ s13023-018-0884-5

23 Thoomes EJ: Effectiveness of manual therapy for cervical radiculopathy, a review. Chiropr Man Therap 24: 45, 2016. PMID: 27980724. DOI: 10.1186/s12998-016-0126-7

24 Cathcart E, McSweeney T, Johnston R, Young H and Edwards DJ: Immediate biomechanical, systemic, and interoceptive effects of myofascial release on the thoracic spine: A randomised controlled trial. J Bodyw Mov Ther 23(1): 74-81, 2019. PMID: 30691766. DOI: 10.1016/j.jbmt.2018.10.006

25 Oh H, Choi S, Lee S, Lee K and Choi J: The effects of manual manipulation therapy on pain and dysfunction in patients with lumbar spinal stenosis. J Phys Ther Sci 32(8): 499-501, 2020. PMID: 32884169. DOI: 10.1589/jpts.32.499

26 Yaseen K, Hendrick P, Ismail A, Felemban M and Alshehri MA: The effectiveness of manual therapy in treating cervicogenic dizziness: a systematic review. J Phys Ther Sci 30(1): 96-102, 2018. PMID: 29410575. DOI: 10.1589/jpts.30.96

27 Simonelli C, Vitacca M, Vignoni M, Ambrosino N and Paneroni M: Effectiveness of manual therapy in COPD: A systematic review of randomised controlled trials. Pulmonology 25(4): 236247, 2019. PMID: 30738792. DOI: 10.1016/j.pulmoe. 2018.12.008

28 Richer N, Marchand AA and Descarreaux M: Management of chronic lateral epicondylitis with manual therapy and local cryostimulation: a pilot study. J Chiropr Med 16(4): 279-288, 2017. PMID: 29276460. DOI: 10.1016/j.jcm.2017.07.001

29 Hall H, Cramer H, Sundberg T, Ward L, Adams J, Moore C, Sibbritt D and Lauche R: The effectiveness of complementary manual therapies for pregnancy-related back and pelvic pain: A systematic review with meta-analysis. Medicine (Baltimore) 95(38): e4723, 2016. PMID: 27661020. DOI: 10.1097/MD. 0000000000004723

30 Arnold P and Bautmans I: The influence of strength training on muscle activation in elderly persons: a systematic review and meta-analysis. Exp Gerontol 58: 58-68, 2014. PMID: 25064039. DOI: $10.1016 /$ j.exger.2014.07.012
31 Courtney CA, Steffen AD, Fernández-de-Las-Peñas C, Kim J and Chmell SJ: Joint mobilization enhances mechanisms of conditioned pain modulation in individuals with osteoarthritis of the knee. J Orthop Sports Phys Ther 46(3): 168-176, 2016. PMID: 26721229. DOI: 10.2519/jospt.2016.6259

32 Wright A, Benson HAE, Will R and Moss P: Cold pain threshold identifies a subgroup of individuals with knee osteoarthritis that present with multimodality hyperalgesia and elevated pain levels. Clin J Pain 33(9): 793-803, 2017. PMID: 27898461. DOI: 10.1097/AJP.0000000000000458

33 Espí-López GV, Arnal-Gómez A, Balasch-Bernat M and Inglés M: Effectiveness of manual therapy combined with physical therapy in treatment of patellofemoral pain syndrome: systematic review. J Chiropr Med 16(2): 139-146, 2017. PMID: 28559754. DOI: $10.1016 /$ j.jcm.2016.10.003

34 Coulter ID, Crawford C, Hurwitz EL, Vernon H, Khorsan R, Suttorp Booth $M$ and Herman PM: Manipulation and mobilization for treating chronic low back pain: a systematic review and meta-analysis. Spine J 18(5): 866-879, 2018. PMID: 29371112. DOI: 10.1016/j.spinee.2018.01.013

35 Wallace IJ, Worthington S, Felson DT, Jurmain RD, Wren KT, Maijanen H, Woods RJ and Lieberman DE: Knee osteoarthritis has doubled in prevalence since the mid-20th century. Proc Natl Acad Sci U.S.A. 114(35): 9332-9336, 2017. PMID: 28808025. DOI: 10.1073 /pnas.1703856114

36 Pieters L, Lewis J, Kuppens K, Jochems J, Bruijstens T, Joossens L and Struyf F: An update of systematic reviews examining the effectiveness of conservative physical therapy interventions for subacromial shoulder pain. J Orthop Sports Phys Ther 50(3): 131-141, 2020. PMID: 31726927. DOI: 10.2519/jospt.2020.8498

37 Anwer S, Alghadir A, Zafar H and Brismée JM: Effects of orthopaedic manual therapy in knee osteoarthritis: a systematic review and meta-analysis. Physiotherapy 104(3): 264-276, 2018. PMID: 30030035. DOI: 10.1016/j.physio.2018.05.003

38 Falsiroli Maistrello L, Rafanelli M and Turolla A: Manual therapy and quality of life in people with headache: systematic review and meta-analysis of randomized controlled trials. Curr Pain Headache Rep 23(10): 78, 2019. PMID: 31401702. DOI: 10.1007/s11916-019-0815-8

39 Page MJ, Green S, McBain B, Surace SJ, Deitch J, Lyttle N, Mrocki MA and Buchbinder R: Manual therapy and exercise for rotator cuff disease. Cochrane Database Syst Rev (6): CD012224, 2016. PMID: 27283590. DOI: 10.1002/14651858.CD012224

40 Weerasekara I, Osmotherly P, Snodgrass S, Marquez J, de Zoete $\mathrm{R}$ and Rivett DA: Clinical benefits of joint mobilization on ankle sprains: a systematic review and meta-analysis. Arch Phys Med Rehabil 99(7): 1395-1412.e5, 2018. PMID: 28882509. DOI: 10.1016/j.apmr.2017.07.019

41 Zavala-González J, Pavez-Baeza F, Gutiérrez-Espinoza H and Olguín-Huerta C: The effectiveness of joint mobilization techniques for range of motion in adult patients with primary adhesive capsulitis of the shoulder: a systematic review and meta-analysis. Medwave 18(5): e7265, 2018. PMID: 30312288. DOI: $10.5867 /$ medwave.2018.05.7265

42 Beumer L, Wong J, Warden SJ, Kemp JL, Foster P and Crossley KM: Effects of exercise and manual therapy on pain associated with hip osteoarthritis: a systematic review and meta-analysis. Br J Sports Med 50(8): 458-463, 2016. PMID: 26612846. DOI: 10.1136/bjsports-2015-095255 
43 Miles D and Bishop M: Use of manual therapy for posterior pelvic girdle pain. PM R 11 Suppl 1: S93-S97, 2019. PMID: 31020812. DOI: $10.1002 /$ pmrj.12172

44 Ramos GA, Arliani GG, Astur DC, Pochini AC, Ejnisman B and Cohen M: Rehabilitation of hamstring muscle injuries: a literature review. Rev Bras Ortop 52(1): 11-16, 2016. PMID: 28194375. DOI: 10.1016/j.rboe.2016.12.002

45 Bade M, Cobo-Estevez M, Neeley D, Pandya J, Gunderson T and Cook C: Effects of manual therapy and exercise targeting the hips in patients with low-back pain-A randomized controlled trial. J Eval Clin Pract 23(4): 734-740, 2017. PMID: 28127827. DOI: $10.1111 /$ jep.12705
46 Fernández-de-Las-Peñas C, Ambite-Quesada S, FahandezhSaddi Díaz H, Paras-Bravo P, Palacios-Ceña D and Cuadrado ML: The Val158Met polymorphism of the catechol-Omethyltransference gene is not associated with long-term treatment outcomes in carpal tunnel syndrome: A randomized clinical trial. PLoS One 13(10): e0205516, 2018. PMID: 30321201. DOI: 10.1371/journal.pone.0205516

Received June 11, 2021

Revised November 6, 2021

Accepted November 8, 2021 